\title{
Kültür Kanıtlı Geç Neonatal Sepsis Olgularında Sıklık, İzole Edilen Mikroorganizmalar ve Antibiyotik Direncinin Araştırılması
}

\section{Investigation of Prevalence, Isolated Microorganisms and Antibiotic Resistance in Cultured Late Neonatal Sepsis Cases}

Hüseyin GÜMÜŞ ${ }^{1}$, Halil KAZANASMAZ ${ }^{1}$

${ }^{1}$ Dr. Öğr. Üyesi. Harran Üniversitesi Tip Fakültesi, Çocuk Sağlığı ve Hastalıkları Anabilim Dalı, ŞANLIURFA

\section{Öz}

Amaç: Yenidoğan sepsisine neden olan etkenler ve antibiyotik dirençleri ünitelere göre farklılık gösterebilmektedir. Bu çalışma yenidoğan yoğun bakım kliniğimizde sepsis tanısıyla takip edilen bebeklerin demografik özellikleri, risk faktörleri, etken mikroorganizmaları ve antibiyotik dirençlerinin araştırılması amaçlanmıştır.

Gereç ve Yöntem: Ocak 2015 ile Mart 2018 tarihleri arasında hastanemiz yenidoğan yoğun bakım ünitesinden mikrobiyoloji laboratuvarına gönderilen 4156 kan kültürü otomatize kan kültürü sistemi ile değerlendirilmişti. İzole edilen mikroorganizmaların antibiyotik duyarlılık testleri Kirby-Bauer disk difüzyon yöntemi ile yapılmıştı. Kültür pozitif neonatal sepsisli olgular çalışmaya dahil edildi ( $\mathrm{n}=237)$. $\mathrm{Bu}$ hastalar erken başlangıçlı neonatal sepsis (ENS) ve geç başlangıçlı neonatal sepsis (GNS) olmak üzere iki gruba ayrıldı. Olgular doğum ağırlığı ve haftası, cinsiyet, risk faktörleri, klinik ve laboratuvar bulguları, kan kültürü, etken mikroorganizma ve antibiyotik direnci yönünden incelendi.

Bulgular: Çalışma döneminde sepsis şüphesiyle bakılan 4156 kan kültürünün 237 'inde $(\% 5,7)$ üreme görüldü. Sepsis tanısı alarak tedavi gören 237 bebek çalışmaya dahil edildi. Olguların 150’i $(\% 63,2)$ geç neonatal sepsis, 87'si $(\% 36,7)$ erken neonatal sepsis tanısı almış olup, 114 olgu (\%76) prematüre idi. Kültürlerde en sık üreyen mikroorganizmalar Klebsiella pneumoniae $(\% 39,3)$, Koagülaz negatif stafilokok $(\% 14,0)$, Escherichia coli $(\% 13,3)$, ve Acinetobacter baumanii $(\% 10,0)$ idi.

Sonuçlar: Geç başlangıçlı neonatal sepsis etkenlerinin zaman içinde değişmesi ve dirençli mikroorganizmaların giderek artması önemli bir sorundur. Bu nedenle her yenidoğan ünitesi geç neonatal sepsis risk faktörlerini, sık görülen etkenleri ve antibiyotik dirençlerini tespit ederek, başlangıç ampirik antibiyotik tedavi planının yapılması önemlidir.

Anahtar Kelimeler: Yenidoğan, neonatal sepsis, antibiyotik direnci

\section{Abstract}

Objective: The factors causing newborn sepsis and antibiotic resistance may differ according to the units. This study aimed to investigate the demographic characteristics, risk factors, causative microorganisms and antibiotic resistance of infants followed up with neonatal sepsis in our neonatal intensive care unit.

Materials and Methods: Between January 2015 and March 2018, 4156 blood cultures sent from our hospital neonatal intensive care unit to the microbiology laboratory were evaluated with an automated blood culture system. Antibiotic susceptibility tests of isolated microorganisms were performed by Kirby-Bauer disc diffusion method. Cases with culture positive neonatal sepsis were included in the study $(\mathrm{n}=237)$. These patients were divided into two groups as early-onset neonatal sepsis (ENS) and late-onset neonatal sepsis (GNS). The cases were analyzed by sex, birth weight and week, risk factors, clinical and laboratory findings, blood culture, active microorganism and antibiotic resistance.

Results: During the study period, sepsis was observed in 237 (5.7\%) cultures of 4156 infants who had blood culture. 237 babies treated with Sepsis were included in the study. 150 cases $(63,2 \%)$ were diagnosed as late sepsis, $87(36,7 \%)$ were diagnosed as early sepsis and 114 cases $(77 \%)$ were premature. The most common microorganisms were Klebsiella pneumoniae $(39,3 \%)$, Coagulase-negative staphylococci $(14,0 \%)$, Escherichia coli $(13,3 \%)$, and Acinetobacter baumanii $(10,1 \%)$.

Conclusion: The change of the sepsis factors and the gradual increase of resistant microorganisms are an important question. For this reason, it is important to determine the neonatal sepsis risk factors, common agents and antibiotic resistance in each newborn unit and make an empirical treatment plan according to these findings.

Key Words: Newborn, neonatal sepsis, antibiotic resistance

\section{GİRIS}

Yenidoğan sepsisi, yaşamın ilk ayında sistemik enfeksiyon bulgularının olduğu ve kandan bir patojenin izole edildiği klinik bir sendromdur (1-3). Geç neonatal sepsis (GNS), prematüre bebeklerde yaşamın 72. saatinden sonra, term bebeklerde yedinci günden sonra ortaya çıan sepsistir (4).

Son yıllarda yenidoğan yoğun bakım ünitelerindeki (YYBÜ) gelişmeler özellikle çok düşük doğum ağırlıklı ve konjenital anomalili bebeklerin hayatta kalma olasılığını

İletişim: Dr. Hüseyin Gümüş. Harran Üniversitesi Tip Fakültesi, Çocuk Sağlığı ve Hastalıkları Anabilim Dalı, Şanlıurfa

DOI:

$10.17517 /$ ksutfd.440633 artırmıştır(5). GNS patogenezinin mekanizması iyi anlaşılmamıştır, ancak bakteriyel kolonizasyon ve düşük gestasyonel yaş önemli risk faktörleridir (6). Bununla birlikte, immün işlev bozukluğu ve transplasental edinilmiş maternal IgG antikorların eksikliği prematüre bebeklerde enfeksiyon riskini artırabilir (7). GNS riskini artıran önemli faktörler, bebekleri yaşatmak için hastanede uygulanan sık aralıklarla kan alma, endotrakeal entübasyon - mekanik ventilasyon uygulamaları, vasküler kateter kullanımı, beslenme için takılan 
sondalar ve uzun süre oral beslenememeye sekonder uygulanan parenteral beslenme gibi invazif işlemlerdir $(6,8)$. Son yıllardaki gelişmelere rağmen sepsis yenidoğan bebeklerde önemli bir mortalite ve morbidite nedeni olmaya devam etmektedir (9). Gelişmiş ülkelerde geç neonatal sepsisli bebeklerin \% 5-10'u, çok geç neonatal sepsisli bebeklerin ise \% 5'inden azı kaybedilmektedir(10). Çok düşük doğum ağırlıklı prematüre bebeklerde geç neonatal sepsisin mortalitesi \% 17-19'dur (11).

Sepsis nedeni olan mikroorganizmaların dağılımı ve antibiyotik duyarlılıkları, her ünitede farklı olabilmekte ve zaman içinde de değişmektedir. Bu nedenle, bakteriyel flora ile ilgili sürveyans ve antibiyotik duyarlılık çalışmaları YYBÜ’ lerdeki sepsis nedeni olabilen mikroorganizmaları ve ampirik antibiyotik tedavi rejimlerini belirleme açısından önemlidir. Bu çalışmada, yenidoğan yoğun bakım ünitemizde izlenen sepsisli olgulardaki etkenler ve antibiyotik dirençleri değerlendirildi.

\section{GEREÇ VE YÖNTEMLER}

$\mathrm{Bu}$ retrospektif gözlemsel çalışma, 2015-2018 yılları arasında III. Basamak yenidoğan yoğun bakım servisinde gerçekleştirildi. Çalışmaya sepsis şüphesi olan 4156 venöz kan kültür örneği alındı. Kan kültüründe üreme olmayan olgular, ilk kan kültüründe üreme olmasına karşın, klinik ve laboratuvar bulguları sepsis tanisiyla uyumsuz olan kontaminasyondan şüphelenilen olgular (sepsis atağı sırasında $>10 \mathrm{mg} / \mathrm{L}$ CRP'de artış olmadığı ve 72 saat içinde antibiyotik tedavisinin geri çekildiği şeklinde tanımlanmış olup bu olguların 2. kan kültürleri negatif olarak doğrulanmıştır), fetal / neonatal alloimmün trombositopeni (FNAITP) veya maternal immüntrombositopenik purpura (ITP), yenidoğan trombositopenisi gibi diğer neonatal trombositopeni nedenleri olan yenidoğanlar, prematürler ve kan değişimi uygulanan olgular çalışma kapsamı dıșında bırakıldı. Gram pozitif ve gram negatif olguların klinik ve hematolojik parametrelerini karşılaştırabilmek için kan kültüründe her iki grup bakteri türüne ait üremesi olan hastalar çalışma kapsamı dişında tutuldu.

Sepsis șüphesi olan tüm olgulardan alınan kültürler, BiomerieuxBact/ alert 3D, kanlı agar, EMB agar ve çikolata agar vasatına ekildi, üreme sonrası antibiyotik direnç ve duyarlılıkları disk difüzyon yöntemiyle değerlendirildi. Ardışık iki kan kültüründe üreme olan 235 hasta çalışmaya dahil edildi. Birden fazla sayıda sepsis atağ atağı çalışmaya dahil edildi.

Verilerin analizi Statistical Packagefor the Social Sciences (SPSS) sürüm 24.0 yazılımı (SPSS Inc, Chicago, IL, ABD) kullanılarak yapıldı. Sürekli değişkenler, verilerin dağılımı ve homojenliği göz önünde bulundurularak Student $t$ testi veya Mann-Whitney U testinden uygun olanı kullanılarak yapıldı. Kategorik değişkenler, Pearsonki-kare veya Fisher'in kesinlik testi ( $2 \times 2$ tabloda gözlenen teorik değerlerden herhangi biri $<5$ olduğunda) kullanılarak analiz edildi.

\section{BULGULAR}

2015-2018 yılları arası kültür kanıtlı 237 sepsis olgusu çalışmaya dahil edildi. 87 (\% 36,7) olgu ENS, 150 (\% 63,2) olgu da GNS olarak gruplara ayrıldı. Cinsiyet dağılımı incelendiğinde, GNS grubunda 91 erkek (\% 60,7), 59 kız ( \% 39,3) bebek olduğu görüldü (Tablo 1). Olgular doğum haftalarına göre sinıflandırıldı̆̆ında; \% 16,0'si $\leq 28$. hafta, $\%$ 21,3's1 29.-33. haftalar aras1, \% 38,7'si 34.-37 haftalar aras1, \%
24 ’ü ise 37 hafta üzeri olduğu görüldü(Tablo 1). Olgular doğum ağırlıklarına göre incelendiğinde \% 12,7’i $\leq 999$ gr, \% 18,0'si 1000-1499 gr arası, \% 32,0’ü 1.500-2499 gr aras1, \% 37,3’i ise $\geq 2.500$ gr idi (Tablo 1).

Tablo 1. Olguların demografik özellikleri

\begin{tabular}{|l|l|l|l|}
\hline & & Olgu sayısı(n) & Yüzde(\%) \\
\hline CINSİYET & ERKEK & 91 & 60,7 \\
& KIZ & 59 & 39,3 \\
& Total & 150 & 100,0 \\
\hline GEBELİK & $<28$ & 24 & 16,0 \\
HAFTASI & $29-33$ & 32 & 21,3 \\
& $68-71$ & 58 & 38,7 \\
& $>37$ & 36 & 24,0 \\
& Total & 150 & 100,0 \\
\hline \multirow{2}{*}{ DOĞUM } & $<999$ gr & 19 & 12,7 \\
AĞIRLIĞI & $1000-1499$ gr & 27 & 18,0 \\
& $1.500-2499$ gr & 48 & 32,0 \\
& $>2.500$ gr & 56 & 37,3 \\
& Total & 150 & 100,0 \\
\hline
\end{tabular}

YYBÜ’nden gelen 4156 kan kültür örneğinin 346’sında $(\% 8,3)$ kontaminasyon; 237'inde (\% 5,7) klinik açıdan anlamlı üreme tespit edilmiştir (Tablo 1). Üreme tespit edilenlerin 150'i $(\%$ 63,2) GNS ve 87’si (\% 36,7) ENS idi.

GNS'de üreme tespit edilenlerin 40'inde (\% 26,7) Gram pozitif bakteriler ve 101 'inde (\% 67,3) Gram negatif enterik ve nonfermenter bakteriler, 9'unda (\% 6,0) Candida spp. saptanmıştır. En sık izole edilen tür, 59 (\% 39,3) ile Klebsiella pneumoniae olarak bulunmuştur (Tablo 2).

Tablo 2. GNS grubunun kan kültür sonuçları

\begin{tabular}{|l|l|l|}
\hline Etken Patojen & Olgu say1sı (n) & Yüzde (\%) \\
\hline S. Aureus & 5 & 3,3 \\
\hline Micrococcus Luteus & 1 &, 7 \\
\hline Klebsiella Pneumoniae & 59 & 39,3 \\
\hline Escherichia coli & 20 & 13,3 \\
\hline Koa(-) Staf. & 18 & 12,0 \\
\hline Acinetobacter Baumanii & 15 & 10,0 \\
\hline Streptococcus Spp & 6 & 4,0 \\
\hline Enterobacter Cloacae & 2 & 1,3 \\
\hline Serratia Liquenfacies & 1 &, 7 \\
\hline Candida & 9 & 6,0 \\
\hline Corynebacterium Spp & 1 &, 7 \\
\hline Pseudomonas Aeroginosa & 1 &, 7 \\
\hline $\begin{array}{l}\text { Sphingomonas Paucimo- } \\
\text { bilis }\end{array}$ & 2 & 1,3 \\
\hline Streptococcus Viridans & 3 & 2,0 \\
\hline Enterokok & 6 & 4,0 \\
\hline Stenotrophomonas & 1 &, 7 \\
\hline $\begin{array}{l}\text { Staphylococcus Epider- } \\
\text { mitis }\end{array}$ & 3 & 2,0 \\
\hline Toplam & 150 & 100,0 \\
\hline
\end{tabular}


Gram pozitif bakterilerin 21'i (\% 52.5) koagülaz-negatif stafilokok (Koa(-) Staf), 6’s1 (\% 15,0) Streptococcus spp, 6’s1 (\% $15,0)$ Enterokok, 5’ü (\% 12,5) Stafilococcus aureus, 2’si (\% 5,0) Streptococcus viridans olarak tanımlanmıştır.

Gram negatif enterik ve nonfermente bakterilerden 59'u (\% 58,4) K. pneumoniae, 20'si (\% 19,8) Escherichia coli, 15'i $(\%$ 14,9) Acinetobacter baumannii, iki olgu E. cloacae, iki olgu Sphingomonas paicimobilis, bir olgu P. aeroginosa, bir olgu da Serratia liquenfacies olarak tanımlanmıştır (Tablo 2).

GNS grubunun kan kültür sonuçları incelendiğinde ise gram pozitif etkenler arasında, 21 olguda Koa(-) Staf en sık izole edilen etken olup 6 olguda Streptococcus spp, 6 olguda da Enterokok izole edildi. GNS grubu gram negatif mikroorganizmalara baktı̆̆ımızda kan kültüründe en sık izole edilen etken 59 olguyla Klebsiella pneumoniae olmuştur. 20 olguda Escherichia coli ve 15 olguda ise Acinetobacter baumanii izole edildi (Tablo 2).

Kültürlerde saptanan mikroorganizmaların antibiyotik dirençlerine bakıldığında, Koa(-) Staf'da Ampisilin \% 75, Seftazidim \% 70, Seftiriakson \% 55,6, Penisilin \% 66.7, Gentamisin \% 28,6, Teikoplanin \% 0, Vankomsin \% 0, Amikasin \% 0 olarak saptand. Teikoplanin Koa(-) Staf \% 0, Streptococcus spp'da \% 0, Vankomisin direnci de ikisinde de $\% 0$ olarak bulundu. Gram negatiflerde Klebsiella pneumoniae ve Escherichia coli için sırasıyla Ampisilin direnci \% 100 ve \% 88,9 , Gentamisin direnci $\% 66,7$ ve $\% 35,0$, Seftazidim direnci $\% 82.5$ ve $\% 52.9$, Sefepim direnci $\% 76.6$ ve $\% 62.5$, Amikasin direnci \% 60.8 ve \% 21.4 bulunurken, İmipenem/Meropenem direnci $\% 44.6$ ve $\% 15.8$, Kolistin direnci $\% 15.4$ ve $\% 0$ bulundu

\section{TARTIŞMA}

Geç neonatal sepsis, bakteriyel, viral veya fungal mikroorganizmalarla gelişen enfeksiyonların bir sonucu olarak karşımıza çıkmaktadır. YYBÜ’lerde GNS olarak tanımlanan hastane enfeksiyonları özellikle prematüre ve düşük doğum ağırlıklı yenidoğanlarda mortalite ve morbidite nedenleri arasında önemli bir yer tutmaktadır (11).

Kara ve arkadaşları (12), düşük doğum ağırlıklı bebeklerde GNS sıklığının arttığı gösterilmiştir. Çalışmamızda kültür pozitifolguların \%37'si 2500 gramüstüydü. Olgularımızın yaklaşık 2/3'ü 2500 gramın altında olup düşük doğum ağırlığ1 ve/veya prematürite tanıları ile ünitemizde izlenmişti. $2500 \mathrm{gr}$ altında doğan bebeklerde sepsis oranının daha yüksek olduğu görüldü.

Prematüre bebekler, invazif girişimlere daha çok maruz kalmaları ve immün sistem yetersizliği nedeni ile enfeksiyona daha eğilimli olmaktadırlar. Solunum desteği verilmesi, sürfaktan uygulanması, göbek kateteri takılması gibi invazif girişimler ve izlem sırasında yapılan medikasyonlar sepsis riskinin daha da artmasına yol açmaktadır $(6,8,13)$. Çalışmamızda, GNS olgularının \% 76'sı prematüre, \% 24’ü, miad olduğu görüldü. GNS'de prematüre olguların belirgin olarak yüksek olduğu tespit edildi.

Sepsis etkenlerinin değişmesi ve dirençli mikroorganizmaların giderek artması önemli bir sorundur. Bulut ve ark.nın (19) 2005 yılında yaptıkları bir çalışmada kan kültüründe en çok üretilen mikroorganizmaların Klebsiella oxitoca (\% 21.2) ve Klebsiella pneumoniae (\% 21.2) olduğu tespit edilmiş. Gürsu ve ark.nın (16) 2005 yılında yaptıkları çalışmada ise GNS olgularının \% 75'inde stafilokok, \% 16.6’sında gram negatif basil tespit edilmiştir. Payaslı ve ark. nın (18) 2007 de yaptıkları çalışmada ise kan kültüründe en çok üretilen mikroorganizma Koa(-) Staf (\% 17.5), \% 10'unda Klebsiella oxitoca, \% 5'inde K. pneumoniae ve sadece bir hastada (\% 2.5) Grup B streptokoklar ürediği tespit edilmiş. Topuz ve ar.nın (17) 2012'de yaptıkları çalışmada GNS olgularında en sık stafilokoklar ve daha az sıklıkta gram negatif basiller ve bir olguda Candida albicans ürediği tespit edilmiş. Kara ve ark.nın (12) 2015 yılında yaptıkları çalışmada GNS tanısı alan olgularda kan kültüründe en sık stafilokoklar (en sık Koa(-) Staf ikinci sıklıkta S. aureus) izole edilirken, ikinci sırada gram negatif basiller ve en az Grup B streptokoklar tespit etmiş. Bizim çalışmamızda, GNS grubunun kan kültür sonuçları incelendiğinde ise; \% 67.3 oranında gram negatif bakterilerle ilişkili olduğu, bunların da \% 39.3'ünde K. pneumoniae, \% 14'ünde Koa(-) Staf, \% 13.3'ünde E. coli, \% 10'nunda ise A. baumanii izole edildiği görülmüştür. GNS sebebi olan mikroorganizmalar aynı ülkede farklı YYBÜ'lerde zaman içinde görülme sıklığı açısından farklı sıralamalar göstermektedir.

Sepsisli hastaların tedavisinde antibiyotik direnci önemli bir sorun olmaya devam etmektedir. Kavuncuoğlu ve ark. (18) tarafından 2011'de yapılan bir çalışmada; K. pneumoniae'de direnç oranları sırasıyla: Ampisilin için \% 82, Gentamisin için \% 34, Amikasin için \% 12, Sefotaksim için \% 46 tespit edilmiştir. Fahmey ve ark.nın (19) 2013’te yaptıkları çalışmada ise; K. pneumoniae için direnç durumu Ampisilin direnci \% 100, Aminoglikozid direnci \% 65 saptanmıştır. Özkan ve ark.nın (20) 2014 yılında yaptıkları çalışmada; K. pneumoniae için direnç durumu sırasıyla: Ampisilin için \% 80, Gentamisin ve Amikasin için \% 20 tespit edilmiştir. Özdemir ve ark.nın (21) 2016 yılında yaptıkları çalışmada ise; S. aureus ve S. epidermidis'de direnç oranları sırasıyla: Penisilin için \% 94.1 ve \% 85.7 Metisilin için \% 82.3 ve \% 85.7 bulunurken; K. pneumoniae'de, Ampisilin ve Gentamisin için \% 92 oranında saptanmıştı. Aynı çalışmada Amikasin, Sefoperazon-Sulbaktam, Meropenem ve Vankomisine dirençli suş bulunmadığı tespit edilmiştir. Bizim çalışmamızda ise; Koa(-) Staf'da Ampisilin \% 75, Seftazidim \% 70, Seftiriakson \% 55.6, Penisilin \% 66.7, Gentamisin \% 28.6, Amikasin \% 0 olarak saptand1. Teikoplanin Koa(-) Staf'ta \% 0, Streptococcus spp'da $\%$ 0, Vankomisin direnci de ikisinde de \% 0 olarak bulundu. K. pneumoniae'de, Ampisilin için \% 100, Gentamisin için \% 66.7, Amikasin için \% 78.3, Sefoperazon-Sulbaktam için \% 50, Meropenem için \% 44.1ve Kolistin için \% 15 oranında direnç saptandı. YYBÜ’mizde GNS'de olası etken patojen ve antibiyotik duyarlılıkları açısından başlangıç tedavisi olarak ampisilin ve gentamisine yüksek direnç sebebi ile vankomisin/ meropenem veya teikoplanin/meropenem kombinasyonu kullanılabilmektedir.

$\mathrm{Bu}$ çalışmayla yenidoğan sepsisi’nin tanısının kültür ile kanıtlanmasının ve antibiyotik duyarlılık testlerinin önemli olduğu vurgulanmıştır. Kültürlerde saptanan mikroorganizmalar ve bu mikroorganizmaların antibiyotik dirençlerinin değişken olabileceği gösterilmiştir. Erkenden fark edilen neonatal sepsis olgularının uygun ampirik tedavi ile sepsise bağlı ölüm oranlarının azaltılabilineceği bilinmektedir. $\mathrm{Bu}$ nedenle yenidoğan üniteleri kültür sonuçlarına göre üniteleri için yenidoğan sepsisinde kendi tedavi stratejileri oluşturmaları gerekmektedir. 


\section{KAYNAKLAR}

1. Dong Y, Speer CP. Late-onset neonatal sepsis: recent developments. Arch Dis Child Fetal Neonatal Ed. 2015; 100: 257-63.

2. Shrestha G, Mulmi R, Joshi N, Shrestha PR. Prevalence of sepsis and possible severe bacterial infection among neonates in Nepal. J Nepal Health Res Counc 2018; 16: 1-5.

3. Davis AL, Carcillo JA, Aneja RK, Deymann AJ, Lin JC, Nguyen TC, et al. American College of Critical Care Medicine clinical practice parameters for hemodynamic support of pediatric and neonatal septic shock. Crit Care Med. 2017; 45: 1061-93.

4. Simonsen KA, Anderson-Berry AL, Delair SF, Davies HD. Early-onset neonatal sepsis.Clin Microbiol Rev. 2014; 27: 21-47.

5. Uslu S, Bolat F, Can E, Comert S, Nuhoğlu A. Yenidoğan yoğun bakım ünitelerinde hastane enfeksiyonlarını önleme çalışmaları. Bakırköy Tıp Dergisi 2010; 6: 1-7.

6. Berrington JE, Stewart CJ, Cummings SP, Embleton ND. The neonatal bowel microbiome in healt hand infection. Curr Opin Infect Dis 2014; 27: 236-43.

7. Kazanasmaz H, Gümüş H. Prematüre Bebeklerde Kültürle Kanitlı Neonatal Sepsisin Klinik ve Laboratuvar Değerlendirmesi. Adıyaman Üniversitesi Sağlık Bilimleri Dergisi.2018; 15: 664-79.

8. Srinivasjois R, Nembhard W, Wong K, Bourke J, Pereira G, Leonard H. Risk of mortality into adulthood according to gestational age at birth. J Pediatr 2017; 190: 185-91.

9. Tzialla C, Manzoni P, Achille C, Bollani L, Stronati M, Borghesi A. New diagnostic possibilities for neonatal sepsis. Am J Perinatol. 2018; 35: 575-7.

10. Edwards MS, Baker CJ. Sepsis in the newborn. In: Gershon AA, Hotez PJ, Katz SL (eds): Krugman's Infectious Diseases of Children (11th ed) Philadelphia: Mosby, 2004: 545-561.

11. Shane AL, Sánchez PJ, Stoll BJ. Neonatal sepsis. Lancet. 2017; 390: 1770-80.
12. Kara H, Ertuğrul S, Gündoğuş N, Akpolat N, Özmen Ö. An evaluation of patients with culture-proven sepsis in a neonatal intensive care unit. Dicle Medical Journal 2015; 42: 355-60

13. Schuchat A, Zywicki SS, Dinsmoor MJ, Mercer B, Romaguera J, O'Sullivan MJ, et al. Risk factors and oppotunities for prevention of early-onset neonatal sepsis: A multicenter case-control study. Pediatrics 2000; 105: 21-26.

14. Gürsu HA. Yenidoğan sepsisi tanısında Serum Amiloid A (SAA)'nın önemi ve CRP ile karşılaştırılması. Uzmanlık tezi. İstanbul, Dr. Lütfi Kırdar Kartal Eğitim ve Araştırma Hastanesi I. Çocuk Sağlığı ve Hastalıkları Kliniği, 2005.

15. Topuz S, Ovalı F. Yenidoğan sepsisinin tanı ve izleminde C-Reaktif Protein ile prokalsitonin değerlerinin karşılaştırilması. Nobel Medicus 2012; 8: 72-76.

16. Payaslı MÖ. Neonatal sepsisli hastalarda polimorfonükleer lökosit elastaz düzeylerinin değerlendirilmesi. Uzmanlık tezi. İstanbul, Haseki Eğitim ve Araştırma Hastanesi Çocuk Sağlığı ve Hastalıkları Kliniği, 2007

17. Bulut MO, Bulut İK, Büyükkayhan D, İçağasıoğlu D, Gültekin A, Toksoy, HB. Neonatal sepsisli olguların retrospektif olarak değerlendirilmesi. CÜ Tip Fakültesi Dergisi, 2005; 27: 63-8.

18. Kavuncuoğlu S, Kazancı S, Yıldız H, Aldemir E, Türel Ö, Ramoğlu M. Yenidoğan yoğun bakım ünitesinde yatan kültür pozitif sepsisli olguların sıklık, etiyolojik faktörler, etken mikroorganizmalar ve antibiyotik direnci yönünden incelenmesi. JOPP Derg 2011; 3: 129-38.

19. Fahmey SS. Early-onset sepsis in a neonatal intensive care unit in Beni Suef, Egypt: bacterial isolates and antibiotic resistance pattern. Korean J Pediatr 2013; 56: 332-7

20. Ozkan H, Cetinkaya M, Koksal N, Celebi S, Hacımustafaoğlu M. Culture-proven neonatal sepsis in preter minfants in a neonatal intensive care unit over a 7 year period: Coagulase-negative Staphylococcus as the predominant pathogen. Pediatrics International 2014; 56: 60-6.

21. Özdemir AA, Elgörmüs Y. Retrospective evaluation of the case swith neonatal sepsis and antibiotic resistance of the causing microorganisms. SETB.2016; 50: 319-324 